\title{
eCOti
DiAno
}

Revista Mídia e Cotidiano

ISSN: 2178-602X

Artigo Seção Livre

Volume 15, Número 1, jan./abr. de 2021

Submetido em: 29/06/2020

Aprovado em: 20/10/2020

\section{O jogo dos falsos tronos: do arquétipo nobre ao estereótipo esnobe}

\section{The game of fake thrones: from the noble archetype to the snobbish stereotype}

\section{El juego de los falsos tronos: del arquetipo noble al estereotipo esnob}

\author{
Marcus Vinicius de PAULA ${ }^{1}$ \\ Lucas Almeida de MELO $^{2}$
}

\section{Resumo}

Trata-se de uma investigação intermidiática que utiliza a teoria iconológica de William Mitchell (1995) para associar as características gráficas e conceituais de um jogo contemporâneo a uma ideologia esnobe e historicista - encontrada em pinturas, romances e folhetins, no século XIX - com o intuito de produzir uma reflexão sobre o consumismo. Questionam-se os fundamentos de uma cultura visual e verbal difusora da necessidade de se adquirir uma identidade aristocrática clichê mascarada por pretensões arquetípicas. $\mathrm{O}$ objetivo é entender em que medida esse modelo, aparentemente arcaico, distante e inócuo, pode ainda reverberar na comunicação visual veiculada numa mídia moderna.

Palavras-chave: Iconologia intermidiática. Pintura acadêmica. Design gráfico de jogos. Consumismo.

\begin{abstract}
This is an intermidiatic investigation that uses William Mitchell's (1995) iconological theory to associate the graphic and conceptual characteristics of a contemporary game with a snobbish and historicist ideology - found in paintings, novels and feuilleton in the 19th century - in order to produce a reflection on consumerism. The fundamentals of a visual and verbal culture spreading the need to acquire a cliché aristocratic identity masked by archetypal pretensions are questioned. The goal is to understand the extent to

\footnotetext{
${ }^{1}$ Professor do Departamento de História e Crítica da Arte e do Programa de Pós-Graduação em Design da Escola de Belas Artes da Universidade Federal do Rio de Janeiro. Mestre em História e Crítica da Arte pela PPGAV-EBA/UFRJ. Doutor em Design pela Pontifícia Universidade Católica do Rio de Janeiro. Email: depaulamarcusvinicius@ gmail.com. ORCID: 0000-0003-4870-9249.

${ }^{2}$ Magna Cum Laude em Licenciatura em Educação Artística - Artes Plásticas, Mestrando em Design pelo Programa de Pós-Graduação em Design da Escola de Belas Artes da Universidade Federal do Rio de Janeiro. Atualmente, cursa o bacharelado em História da Arte na mesma instituição e Especialização em Ensino Contemporâneo de Arte pela Faculdade de Educação e Colégio de Aplicação da UFRJ. Email:lmelo496@gmail.com. ORCID: 0000-0001-8518-8839.
} 
which this apparently archaic, distant and innocuous model can still reverberate in the visual communication conveyed by modern media.

Keywords: Intermidiatic iconology. Academic painting. Games graphic design. Consumerism.

\section{Resumen}

Tratamos de una búsqueda intermedial que utiliza la teoría iconológica del William Mitchell (1995) para la asociación de los rasgos gráficos y conceptuales de un juego contemporáneo a una ideología esnob e historicista - encontrada en las pinturas, novelas y folletines del siglo XIX - con la intención de producir una reflexión sobre el consumismo. Cuestionarse los fundamentos de una cultura visual y verbal difusora de la necesidad de adquirirse una identidad aristocrática cliché enmascarada por pretensions arquetípicas. El objetivo es comprender en qué medida ese modelo, aparentemente arcaico, lejano e inocuo, puede aun reverberar en la comunicación visual vehiculada a media moderna.

Palabras clave: Iconología intermedial. Pintura académica. Diseño gráfico de Juegos. Consumismo.

\section{Introdução: academicismo e comunicação visual}

Ao se visitar uma loja especializada em jogos de cartas e tabuleiro (Figura 1) pode-se ter a esdrúxula sensação de estar dentro de uma versão pós-industrial dos salões de pintura acadêmica do século XIX. Ironicamente, todas aquelas ilustrações repletas de referências historicistas, expostas em profusão nas estantes, parecem remeter à tela de François-Joseph Heim (Figura 2), na qual Carlos X entrega condecorações, em um cômodo apinhado de quadros do chão ao teto. 


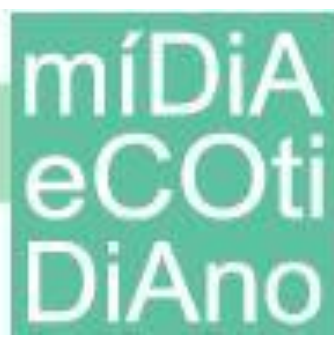

\section{PPGMC \\ uff}

Figura 1 - Detalhe do aspecto geral de uma típica loja de board games

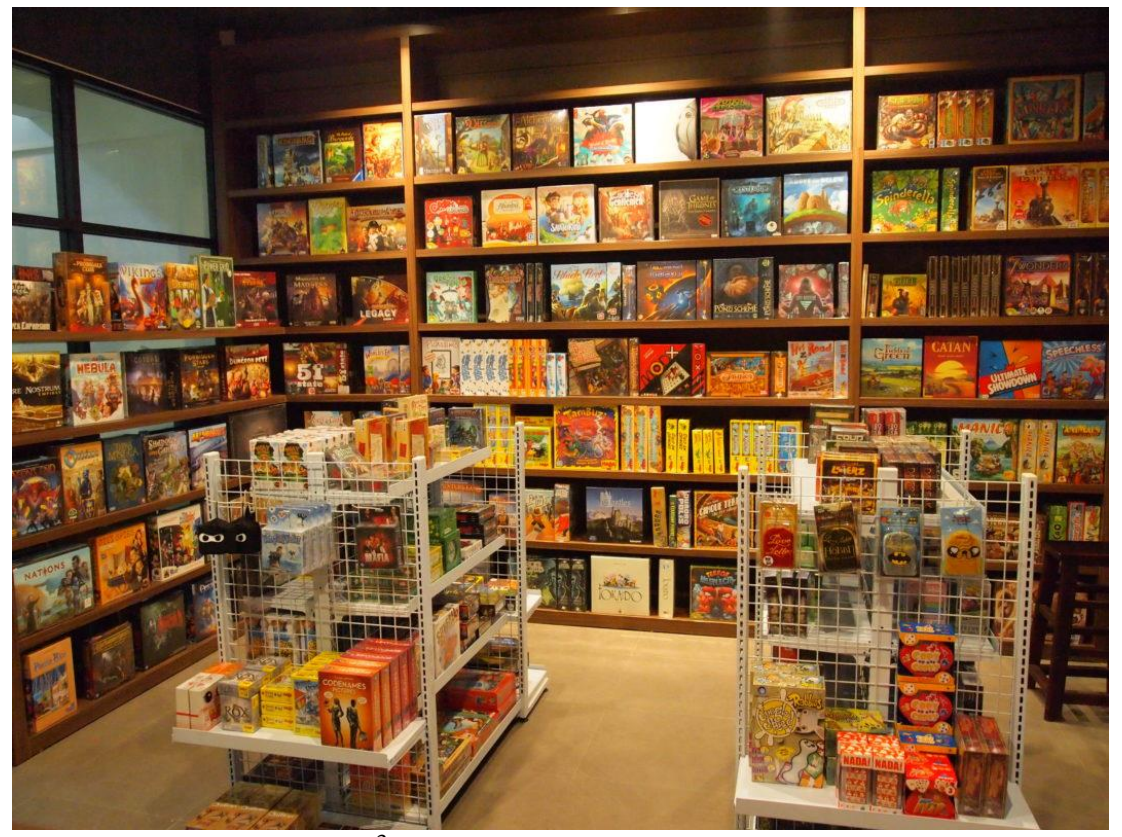

Fonte: Google imagens ${ }^{3}$.

Figura 2 - Carlos X entregando prêmios no Salão de 1824 (1827), de François-Joseph Heim (173 cm x $256 \mathrm{~cm}$ ), Museu do Louvre

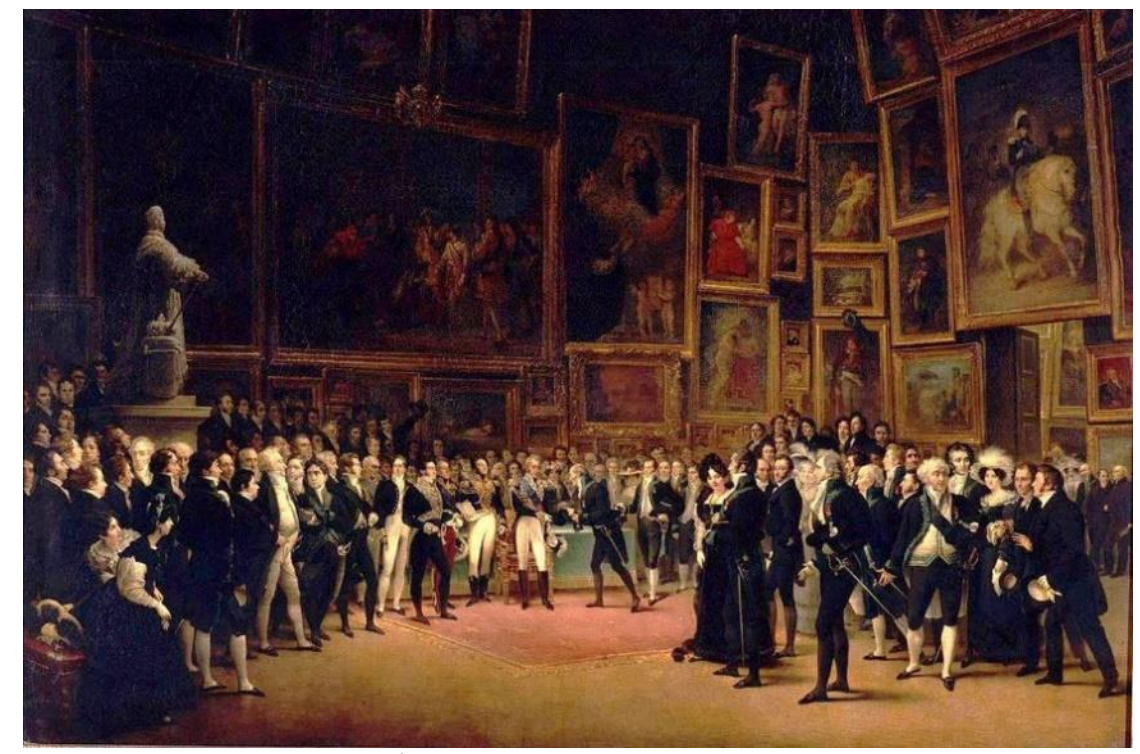

Fonte: Google imagens ${ }^{4}$.

\footnotetext{
3 Disponível em: https://www.tabletopday.com/listings/tabletoys-board-game-store-and-library/. Acesso em: outubro de 2020.

4 Disponível em: https://pt.wahooart.com/@@/8XZGXB-François-Joseph-Heim-Carlos-V-PrêmiosDistribuidoras-aos-artistas-no-encerramento-do-Salão-de-18. Acesso em: outubro de 2020.
} 
Parece ser um indício de que algumas características estéticas associadas ao academicismo talvez estejam sendo reutilizadas por alguns setores da comunicação visual $^{5}$ moderna, ou seja, mídias ${ }^{6}$ contemporâneas estariam reproduzindo (ou relendo) modelos arcaicos. Gostaríamos de destacar um jogo específico, cuja temática lida com intrigas cortesãs, denominado The Last Banquet (projetado, em 2014, por Michael Nietzer, Oliver e Britta Wolf e design gráfico de Simon Eckert). No verso da caixa existem explicações sobre o conteúdo composto por cartas, ilustrando os diversos personagens e fichas com brasões e objetos heráldicos que poderiam servir como estímulos para as tais conspirações que fundamentam a mecânica do jogo. Na maior face da tampa da caixa (Figura 3) está retratada uma cena palaciana centrada na figura de um rei coroado, sentado diante de uma mesa de banquete e cercado por elegantes convivas.

A indumentária e os objetos cênicos estão cuidadosamente apresentados e remetem à cultura cortesã europeia de diversas épocas que vão do século XV ao XIX. Hoje relacionaríamos, de modo mais imediato, ao imaginário dos contos de fadas dos longas-metragens da Disney, mas gostaríamos de revolver outras camadas mais profundas do que essa.

\footnotetext{
${ }^{5}$ A expressão "comunicação visual", aqui, possui um sentido muito mais amplo que sua definição modernista tradicional, pois engloba questões associadas à narrativa e à figuração.

${ }^{6}$ A palavra "mídia" tem sido largamente utilizada para tratar exclusivamente dos meios de comunicação de massas que surgiram após a Revolução Industrial. Entretanto, o termo pode ser empregado num sentido mais amplo que inclui qualquer suporte de difusão de informação capaz de transmitir mensagens. Neste artigo realizaremos uma experiência intermidiática que contrapõe uma mídia contemporânea (um jogo moderno produzido em larga escala por meio de técnicas gráficas atuais) e um meio de comunicação visual que teve sua origem numa era pré-industrial (a pintura acadêmica), mas que, no século XIX, foi afetado por transformações que deram origem à cultura de massa.
} 


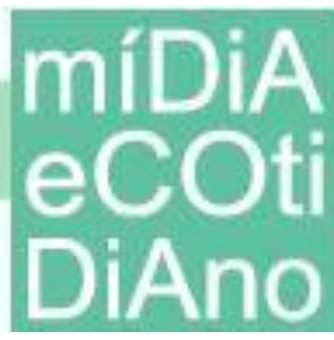

\section{PPGMC}

uff

Figura 3 - Face superior da tampa do jogo The Last Banquet

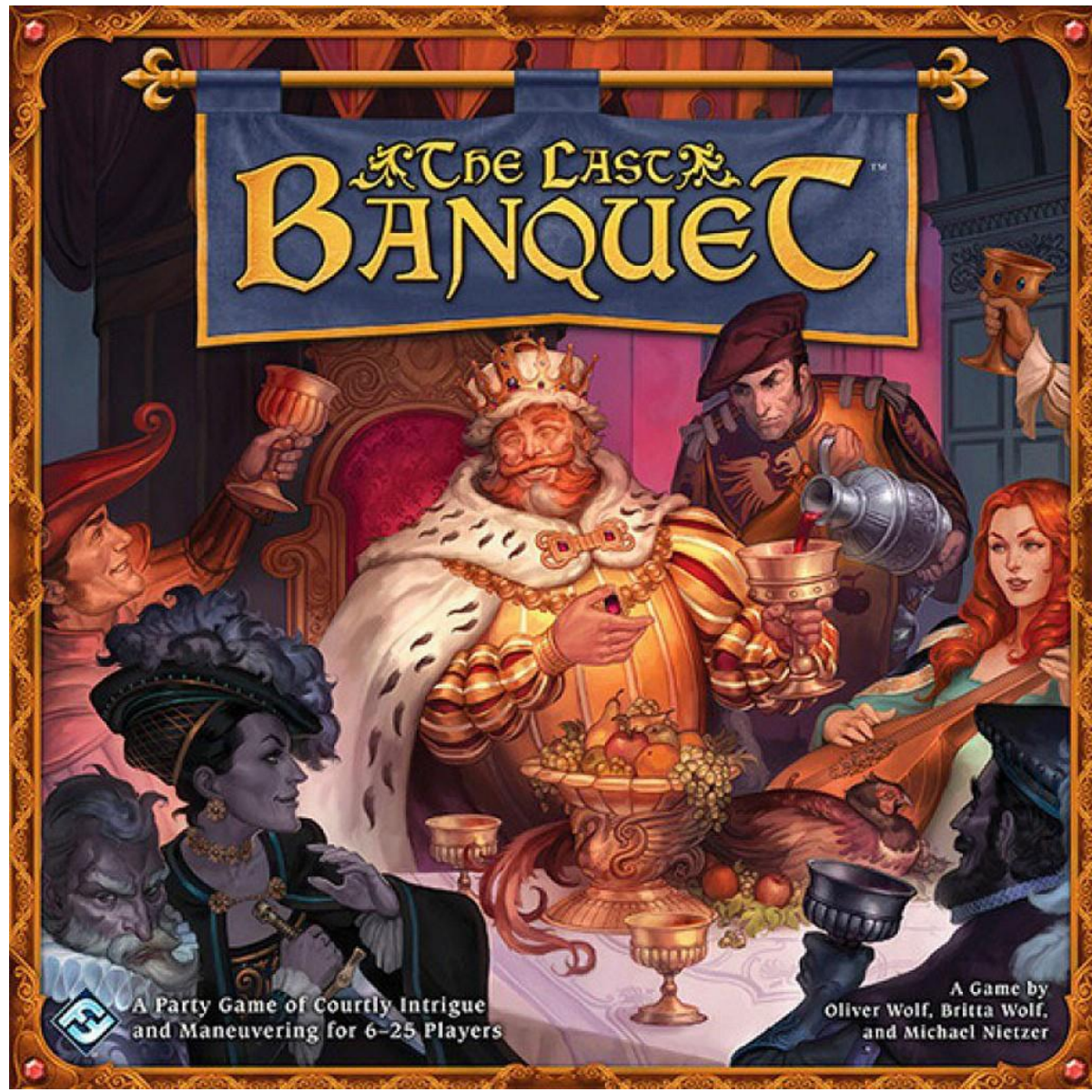

Fonte: Fotografia dos autores.

A cena está cercada por uma suntuosa moldura dourada. A composição e o tema da ilustração central, em certo sentido, remetem ao gosto acadêmico da segunda metade do século XIX, o qual associamos a pintores, como Franz Geyling, Cesare Augusto Detti e Jean-Georges Vibert, para citar apenas alguns. Acima dessa imagem, o título do jogo sobrevoa o grupo como se fosse um luxuoso estandarte escrito com tipografia de inspiração medieval e sustentado por hastes ornamentadas com flores-de-lis. Aquela estética eclética e historicista que enchia os olhos do público do século XIX com objetivo de reviver um passado arqueologicamente opulento (ambientes, vestuário e objetos cênicos) parece ter sido relida pelo design gráfico de jogos.

Entretanto, a princípio, a ilustração da tampa de um jogo exposta na prateleira de uma loja no século XXI não desfruta da mesma notoriedade que uma pintura, quando era exibida nos salões do século XIX. Dizemos “a princípio” porque essas obras e artistas 


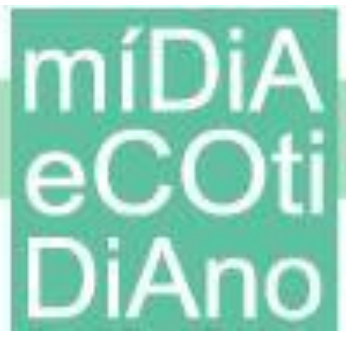

associados ao academicismo foram destronados pela história da arte moderna e perderam esse status. Paradoxalmente, o período em que o prestígio acadêmico da pintura histórica ${ }^{7}$ atingiu o ponto máximo na cultura visual ocidental, é também o momento em que começa a ser tachada como veículo de uma retórica excessivamente eloquente e kitsch ${ }^{8}$. Pouco a pouco foi transformando-se em uma mídia pretenciosa, na mediada em que continuava a ser exibida com solenidade nos salões, mas vinha sendo considerada, pela crítica moderna, como mero pastiche, composto por uma iconografia clichê.

Portanto, para que possamos comparar o vocabulário da pintura figurativa do século XIX aos ícones estereotipados da cultura de massa no século XXI (como os que vemos em The Last Banquet) será preciso, antes, compreender o processo de banalização sofrido pela arte acadêmica.

\section{A banalidade pomposa na pintura de gênero histórico}

A pintura de gênero histórico tem sido, algumas vezes, caracterizada, meramente, como o resultado da contaminação da complexa linguagem visual da pintura histórica monumental pela narrativa banal e frívola, típica das pequenas pinturas de gênero. No gênero histórico “os episódios históricos são tratados de modo mais informal”, "um modelo de realismo anedótico", mais trivial (ALVIM, 2010, p. 90).

Um exemplo evidente disso é a tela Henrique IV e seus filhos, pintada por Pierre Révoil em 1817 (Figura 4), que mostra o rei da França, no início do século XVII, sendo surpreendido por um embaixador enquanto brinca com seus filhos como se fosse um pai de família pertencente às classes médias do século XIX. Não se trata, portanto, de um grande evento histórico, mas de um momento qualquer ordinário. A tela cria, então, uma empatia entre aquele personagem - que as tradições europeias conferiram virtude aristocrática - e o espectador comum que, dentro dos parâmetros dessa mesma cultura, não possuiria essa identidade privilegiada.

\footnotetext{
${ }^{7}$ A pintura histórica foi uma prática artística que se consolidou dentro do contexto das academias de belasartes e pode ser definida como uma modalidade de pintura voltada para a narrativa de temas eruditos (religiosos, alegórico-mitológicos e extraídos da história da cultura). Para mais esclarecimentos sobre esse assunto, conferir Lichtenstein (2006).

${ }^{8}$ Categoria estética que se caracteriza pelo uso excessivo de estereótipos e clichés.
} 
Stephen Bann amplia essa definição restrita e informa que Paul Delaroche em conjunto com a escola de pintores de Lyon (apelidados de "Trovadores") foram os responsáveis por reformular os códigos heroicos e grandiloquentes definidos por JacquesLouis David (BANN, 1997, p. 93), rompendo com os arquétipos ${ }^{9}$ iconográficos eruditos e os substituindo por uma tipologia estereotipada, romanesca, e mais próxima de um vocabulário que as massas estavam mais acostumadas. O sensacionalista Delaroche, "pintor da corte de todas as majestades decapitadas" (BANN, 1997, p. 154), teria "entendido muito bem a contribuição precisa que o pintor tinha a oferecer, naquele momento, para o desenvolvimento de uma cultura histórica de massa" (BANN, 1997, p. 106) ${ }^{10}$.

Figura 4 - Henrique IV e seus filhos (1817) de Pierre Révoil, Castelo de Pau, França

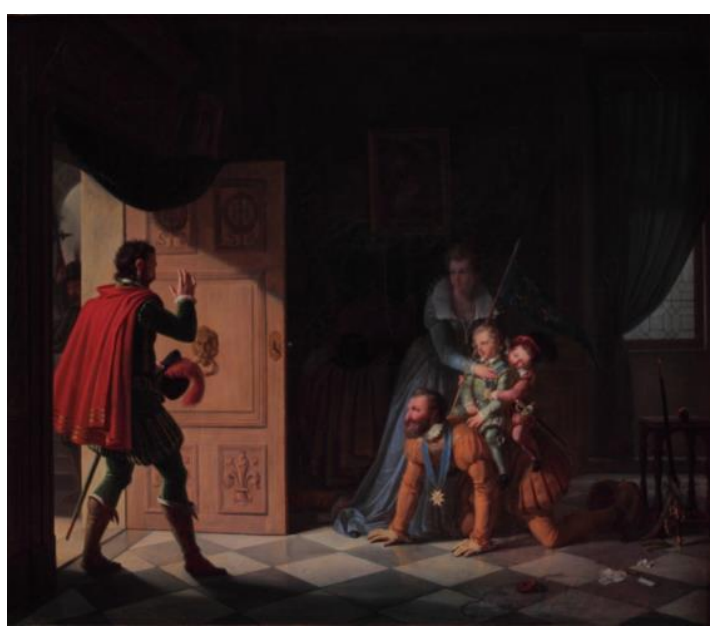

Fonte: Useum ${ }^{11}$.

\footnotetext{
9 A noção de "arquétipo" que estamos utilizando aqui se refere a um modelo que alguma tradição determinou como um exemplo singular, ilustre e possuidor de uma qualidade primordial elevada acima das contingências. Portanto, é uma noção contraditória, pois todo o valor essencial que possui é uma invenção histórica.

${ }^{10}$ Seguindo esses interesses, Bann (1997, p. 185) informa que, ao pintar a pequena tela do Cardeal de Richelieu, em 1829, Delaroche não estava pintando o fato histórico, mas uma cena inspirada no romance Cinq-Mars (publicado em 1826), de Alfred Vigny, o primeiro escritor francês a absorver o estilo folhetinesco de Walter Scott. Norbert Wolf (2012, p. 110-111, 160, 179-180) confirma que esse gênero histórico de pintura assimilou certas estratégias literárias do folhetim.

${ }^{11}$ Disponível em: https://useum.org/artwork/Henri-IV-and-His-Children-Pierre-Revoil-1813. Acesso em: outubro $/ 2020$.
} 
No entanto, ao que tudo indica, o grande divulgador da pintura de gênero histórico parece ter sido Ernest Meissonier. A produção desse artista foi considerada, ainda no século XIX, "estupidez ilimitada de burgueses e novos ricos” (GOTLIEB, 1996, p. 2). Ele foi acusado de ter transformado a pintura em mercadoria que "destruiu a grande tradição do Salão Francês" (GOTLIEB, 1996, p. 10). No entanto, o sucesso de Meissonier residia "precisamente na modéstia de sua ambição [...] estreita [...] evitando temas literários e filosóficos" (GOTLIEB, 1996, p. 14). Suas telas mostravam cenas banais com figuras anônimas com pomposos trajes históricos, mas que podiam ser, também, interpretadas como "atores vestidos com roupas de época” (GOTLIEB, 1996, p. 119).

Entendemos que as majestosas e majestáticas figuras históricas representadas naquelas telas passaram a ser reconhecidas como alter egos das classes burguesas, pois o espectador, pertencente à alta ou à pequena burguesia, diante das telas de gênero histórico, tinha a sensação de que aquelas imagens carregavam uma fórmula mágica que permitiria a aquisição de uma identidade ilustre. No entanto, paradoxalmente essa fórmula se baseava na ausência da mesma identidade que a imagem indicava. A ausência é o fundamento de todo o desejo de consumo, sugere Jean Baudrillard (2004, p. 184-187). É justamente essa carência - que irá fundamentar o espírito esnobe ${ }^{12}$ dessas imagens e a relação entre o consumismo e o historicismo no século XIX, conforme trataremos a seguir.

\section{A invenção da história}

Norbert Elias sugere que a identidade aristocrática formulada pela nobreza feudal europeia se baseava num abismo entre essa classe social e as classes servis (ELIAS, 2001, p. 198-199). Jacques Le Goff, por sua vez, mostra que a história medieval tem início com a destruição da classe média urbana que existia no Império Romano (LE GOFF, 2005). Por conseguinte, os requintados bens de consumo (manufaturas flamengas e francesas) que, tempos mais tarde, abasteceriam as cortes feudais - a partir do final da

\footnotetext{
12 No sentido estrito da palavra que indica a falta de nobreza e a decorrente necessidade incessante de preencher esse vazio.
} 
Idade Média ${ }^{13}$ até o século XVIII ${ }^{14}$ - serviriam para ratificar, por meio de códigos visuais (indumentária, joias, objetos de decoração, etc.), a enorme desigualdade que já havia entre as famílias senhoriais e os camponeses. Foi esse hiato, profundo entre as classes, conseguiu fazer com que a nobreza construísse uma imagem altamente ilustre (no sentido de brilhante e notável) e extremamente arrogante e excludente ${ }^{15}$.

As burguesias, por sua vez, surgem nesse período como uma nova classe intermediária e, por isso, não possuía identidade, na medida em que ocupava o lugar do hiato que definia a própria diferença entre nobres e servos. Nesse sentido, ser burguês significava não ter um lugar fixo e sedimentado dentro da sociedade feudal. Esta não era considerada uma classe diferenciada, mas uma condição acidental; possuía, portanto, uma falta de identidade ou uma identidade crítica. George Duby (1982) explica de modo detalhado a construção do imaginário feudal francês e a estratificação social em três ordens: o clero, a nobreza e os servos. Dentro desse panorama, a burguesia francesa foi obrigada a se submeter às leis suntuárias e se inserir desconfortavelmente no Terceiro Estado, juntamente com os camponeses. A partir dessas observações, foi possível inferir que a ascensão desse grupo social resulta em estratégias para superar essa falta de identidade.

No século XIX, vários grupos sociais recém-enobrecidos, cujos modelos fundamentais são as elites napoleônicas (BANN, 1994, p. 120-122) e as autoridades estatais da Monarquia de Julho e do Segundo Império, contribuíram para a instituição de uma estética que Stephen Bann (1994, p. 20) denomina como "invenção da história". O autor explica que é um conceito distinto da "invenção da tradição", desenvolvido por Eric Hobsbawn em 1983, pois não se trata de uma mera falsidade, mas de perceber que a partir do século XIX toda história será uma reconstituição histórica, um ressuscitar, um reviver

\footnotetext{
${ }^{13}$ Segundo Marina Belozerskaya (2012, p. 48-58), a identidade visual ilustre da nobreza foi formulada a partir do período feudal e se consolidou no final da Idade Média, a partir da dinastia Valois, principalmente a corte dos duques da Borgonha que, desejando aparentar maior nobreza que o Rei da França, construiu uma cultura visual totalmente focada nesse interesse.

${ }^{14}$ Estamos nos referindo ao sistema de produção de luxo aristocrático mercantilista que teve origem na era de Luís XIV (DENIS, 2000, p. 22-23).

15 “(...) na Idade Média, era parte inseparável da existência dos ricos que existissem também camponeses e artesãos trabalhando para eles, e mendigos e aleijados com mãos estendidas. Não há para o nobre nenhuma ameaça nisso nem ele se identifica com eles.” (ELIAS, 2001, p. 196).
} 
(um revivel). No entanto, os dois conceitos estão extremamente interligados, na medida em que essa ressurreição histórica foi motivadora de todo o historicismo que produziu, no século XIX, bens de consumo (pinturas, romances, objetos utilitários, edifícios, etc.) revestidos por signos de um falso passado aristocrático. Na sociedade burguesa industrial, as mercadorias estavam hipertrofiadas com ornamentos que remetiam àquela comunicação visual do luxo arrogante, construída pela nobreza europeia desde o final da Idade Média. O epíteto dessa invenção da história ocorria quando algum burguês recebia um título de nobreza, fundamentado nos códigos feudais, e se transformava artificialmente em personalidade histórica ${ }^{16}$, do mesmo modo que uma casa moderna era construída com ornamentos medievais.

Por meio de uma alegoria tortuosa, pode-se dizer que Drácula, de Bram Soker (publicado em 1897) traduz a crise que envolve essa questão ${ }^{17}$. Esse romance neogótico inverte o modelo das novelas históricas - e também das pinturas históricas - que transportam o espectador ou personagens para o passado. O conde Drácula, ao contrário, é um nobre medieval que anacronicamente vive uma aventura monstruosa no presente (no caso, o século XIX). Pode-se dizer que ele é, na verdade, a antítese de um conde, pois sua nobreza foi corrompida e invertida. Portanto, em vez de possuir uma identidade ilustre, diferenciada das classes servis, não possui nenhuma autoimagem. O espelho vazio está diretamente ligado ao fato de não contar com serviçais. O conde é odiado pelos camponeses, que não reconhecem sua superioridade social. Assim, do poder senhorial conferido pelo título de nobreza, restou apenas um castelo em ruínas e o terror. Drácula torna-se um esnobe, por excelência, pois o que o define não é o que ele é, mas o que lhe falta: a nobreza ilustre.

Sem a posse efetiva de uma imagem pessoal, esse vampiro terá de se alimentar vorazmente de outras identidades, consumindo de modo insaciável a essência vital de

\footnotetext{
16 O conceito de "história" utilizado aqui é uma noção propositalmente ultrapassada e está diretamente relacionado à história oficial, construída pelas elites europeias. Proust (2002, p. 172) coloca essa questão da relação entre o título de nobreza associado a um indivíduo e a identidade histórica que esse título carrega: "a duquesa de Guermantes se assentara. Seu nome, como era seguido pelo título, ajuntava à pessoa física o seu ducado (...) sentia-me espantado que a semelhança não fosse mais legível no rosto da duquesa (...) as sardas (...) deveriam estar brasonadas" O título de nobreza no século XIX pode ser considerado um ornamento historicista agregado à personalidade do indivíduo.

${ }^{17}$ Inclusive, a teoria de Stephen Bann (2010, p. 8-31) implica num ressuscitar do passado que está associado a animais empalhados, ou seja, cadáveres que mantém a aparência de vida.
} 
suas vítimas. Em contradição com o simbólico sangue azul da nobreza, Drácula não possui sangue algum. Desse modo, seu título de conde não possui lastro. É um título vazio. Para agravar ainda mais essa situação, grande parte do sangue que consome é dos camponeses plebeus. Porém, é por meio desse consumo incessante, que esse cadáver sem alma consegue resgatar uma pequena porção da aparência do heroico personagem histórico que um dia foi. A crise de identidade desse personagem é um mórbido comentário às avessas sobre o artifício historicista envolvido na construção da autoimagem dos pseudocondes (burgueses recém-enobrecidos) ${ }^{18}$.

O que fica também subentendido no texto de Bann (1994), e que está também diretamente relacionado a essa alegoria do conde degenerado, é que essa estética da "invenção da história" se difundiu como um modismo não apenas na pequena e na alta burguesia, mas também, de modo paradoxal na tradicional nobreza de origem feudal europeia $^{19}$, ou seja, em todas as camadas de consumidores. Desse modo, mesmo as famílias com passado aristocrático, considerado legítimo, passaram a significar esse passado por meio de signos de uma história inventada ${ }^{20}$.

Sendo assim, no século XIX, todos se tornaram esnobes. Enquanto príncipes de sangue real e barões banqueiros construíam falsos castelos, todas as classes com poder de compra liam novelas de Walter Scott e folhetins ilustrados de Alexandre Dumas pai (WOLF, 2012, p. 96). Além disso, todos se deliciavam nas exposições universais. Nessas grandes feiras, os bens de consumo - novos, mas decorados com ornamentos historicistas pretensiosamente suntuosos - produzidos em larga escala encontravam sua legitimação ideológica na simultaneamente pomposa e banal comunicação visual da pintura de gênero histórico que era exibida dentro desse mesmo contexto.

\footnotetext{
${ }^{18}$ O Conde de Monte Cristo, de Alexandre Dumas, coloca essa mesma questão de outro modo. No romance, um simples marinheiro inventa uma história para assumir a identidade de um conde fictício. Mais de uma vez, Dumas (2008, p. 348-349) compara o protagonista a um vampiro: "se houvesse algum homem que pudesse fazer acreditar na existência dos vampiros era aquele"; "estou vendo que o meu vampiro não passa de um homem que enriqueceu há pouco, que quer que lhe perdoem os seus milhões (...) para não ser confundido com o barão de Rothschild.” (p. 377-378).

${ }^{19}$ A aristocracia do início do século XX vive uma vida tão esnobe e burguesa quanto qualquer novo rico: "seu ódio aos esnobes decorria de seu esnobismo" (PROUST, 2002, p. 417).

${ }^{20}$ Vale citar, como exemplo, tanto o Palácio da Pena, em Portugal, quanto o Castelo de Neuschwanstein, na Baviera. Ambos, claramente "histórias inventadas", foram construídos por iniciativa de membros das famílias reais europeias.
} 
Aquele lugar inadequado, entre as classes menos favorecidas e a aristocracia, que havia sido imposto à burguesia no final da Idade Média foi se transformando numa promessa de ascensão ${ }^{21}$, ou seja, a burguesia construiu, para ela mesma, uma promessa de afastamento das classes servis e aproximação da nobreza. Porém, como no século XIX grande parte da antiga aristocracia feudal havia assumido um modo de vida burguês, a promessa de identidade que a estética da "invenção da história" tinha a oferecer não se apresentava mais como uma possibilidade.

Assim, os consumidores (antigos e novos aristocratas, burgueses e pequenos burgueses) passaram a utilizar seu poder de compra para adquirir uma identidade que não estava disponível no mercado. Por esse motivo, a possibilidade de comprar uma autoimagem não poderia se consumar nem mesmo quando o burguês conseguisse edificar um castelo neogótico, mandasse pintar um retrato aristocrático ${ }^{22}$, ou adquirir um título de nobreza, simplesmente porque as condições sociais do final da Idade Média e do Antigo Regime não existiam mais ${ }^{23}$. Sendo assim, tanto as elites quanto as classes médias, aburguesadas, passaram a habitar aquele antigo hiato e, por esse motivo, todos se tornaram mercado consumidor para histórias inventadas. A partir de então, somente esse consumismo ávido e incessante poderia lhes conferir identidade ilustre ${ }^{24}$. Sem esse artifício, tal como Drácula, não conseguiriam se enxergar no espelho.

\footnotetext{
${ }^{21}$ Sem o feitiço da invenção da história, essa promessa teria sido inviável. No século XVII, Le Bourgeois Gentilhomme, segundo Molière, era uma figura ridícula e sem acesso às camadas mais ilustres da sociedade.

${ }^{22}$ Norbert Wolf (2012, p. 53) lembra que Alexander Cabanel retratou inúmeras burguesas utilizando os códigos visuais dos retratos da aristocracia e da realeza, fazendo com que essa classe social nouveaux riches (como ele chama) emulasse outra identidade.

${ }^{23}$ Certamente, ninguém retrata essa circunstância melhor do que Honoré de Balzac. Segundo Herbert J. Hunt, um dos sentidos das "ilusões perdidas" é o fracasso do processo de enobrecimento de Lucien Chardon (BALZAC, 2016, p. 14, 17, 19). O personagem central se desilude com o cruel esnobismo da aristocracia rural e urbana.

${ }^{24}$ Nada melhor para exemplificar essa suposição do que a compulsão por antiguidades que se apossou do barão James de Rothschild, como relata Derek Wilson (1994, p. 109): "for James, collecting was an obsession (...) all manner of antiques and objets d'art, he continued to by - continuously and compulsively."
} 


\section{Entre o arquétipo nobre e o estereótipo esnobe}

A partir dessa discussão sobre a identidade aristocrática, caberia agora perguntar se o rei de The Last Banquet, (que não é rei de coisa alguma, porque não é relativo ou regional, mas absoluto), deve ser entendido como um arquétipo de nobreza, ou seja, modelo ideal singular e superior a todos os casos particulares de reis, ou meramente um estereótipo popular e banal de nobre (modelo simplificado baseado em casos particulares mais complexos)?

Para responder a essa questão é preciso que compreendamos, com maior profundidade, o processo de consolidação do status arquetípico assumido pela nobreza europeia e a crise que se instaura no século XIX. Peter Burke (2009, p. 16) relata com detalhes a eficiente construção da imagem do Rei Sol (e sua corte) num tempo em que a noção cínica de propaganda ainda não existia e, por isso, era possível estabelecer um modelo ilustre e ideal de um rei absoluto (e não relativo) que derramava sua aura arrogante e arquetípica sobre toda a nobreza que o cercava ${ }^{25}$.

Em Em Busca do Tempo Perdido (PROUST, 2002), de Marcel Proust, a situação é outra. Trata-se de uma obra que pode ser considerada como uma desconstrução do romance histórico no qual a coerência da reconstituição do passado, que em Walter Scott assumia uma linearidade de causa e efeito, se torna uma narrativa desconexa e irrecuperável. Mesmo no último volume - O Tempo Recuperado o que se encontra é um baile de fantasmas no qual todos os personagens envelhecidos e irreconhecíveis aguardam a morte (não somente a finitude de suas existências físicas, mas também de suas identidades históricas). Após a Primeira Grande Guerra, período em que se desenrola esse último episódio, a invenção do passado não servirá mais para comprar uma identidade ilustre.

Esse baile final pode ser comparado a outro baile (à fantasia), citado No Caminho de Guermantes, que se passa no final do século XIX, quando o duque de Guermantes se veste de Luís XI e a duquesa, de Isabel da Baviera (PROUST, 2002, p. 473), indicando uma coerência entre o personagem contemporâneo e o histórico (que se encaixam como

\footnotetext{
${ }^{25}$ Peter Burke (2009, p. 18) afirma que Luís XIV era "constantemente comparado com deuses e heróis da mitologia clássica” e isso transformava-o num personagem arquetípico.
} 
identidades arquetípicas para a nobreza dos duques). Tanto Luís XI quanto Isabel da Baviera reinaram no período final da Idade Média, ou seja, no momento em que a nobreza francesa formulou toda uma comunicação visual ilustre por meio do luxo. Portanto, deduz-se que seriam fantasias faustosas.

É, entretanto, importante constatar que, na época em que Proust escreveu seu livro, Luís XI era reconhecido pelas multidões como vilão de Quentin Durward, um famoso romance de Walter Scott, publicado em 1823. Isabel da Baviera, por sua vez, fora personagem-título de um folhetim escrito por Alexandre Dumas pai, em 1835, ou seja, ambos já eram clichês da cultura de massa. Subitamente, os gloriosos arquétipos se revelam como meros estereótipos. Toda a coerência, que parecia unir a vida dos personagens às sólidas narrativas históricas ${ }^{26}$, apresenta-se como um tolo artifício incapaz de impedir a decrepitude de todos esses mesmos personagens no último baile. Proust nos induz a perceber que mesmo os indivíduos da aristocracia com seus nomes e títulos hereditários, aparentemente tão plenos de identidade arquetípica, enfrentam uma crise de autorreconhecimento na Modernidade.

Com o intuito de trazer a discussão para o âmbito da comunicação visual, tomemos a pequena tela de Cesare Auguste Detti ${ }^{27}$, de gênero histórico, pintada em 1895 e denominada $O$ Casamento do Príncipe (Figura 5).

\footnotetext{
${ }^{26}$ Semelhante à associação que Luís XIV fazia, por exemplo, entre sua identidade arquetípica, de Rei Sol, e a de Alexandre Magno (BURKE, 2009, p. 80).

27 Segundo Janet Whitmore (2016), o ilustrador de livros de Walter Scott e pintor de gênero histórico, Cesare Augusti Detti (1847-1914), foi contratado pelo famoso marchand Adolph Goupil (1806-1893), em 1876, para pintar telas pequenas que valorizavam intrincados figurinos de época. Essas imagens eram também transformadas em gravuras acessíveis à classe média.
} 


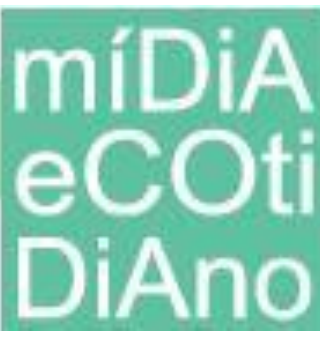

PPGMC

uff

Figura 5 - The Marriage of the Prince (1895) de Cesare Auguste Detti $(167$ x $138 \mathrm{~cm})$.

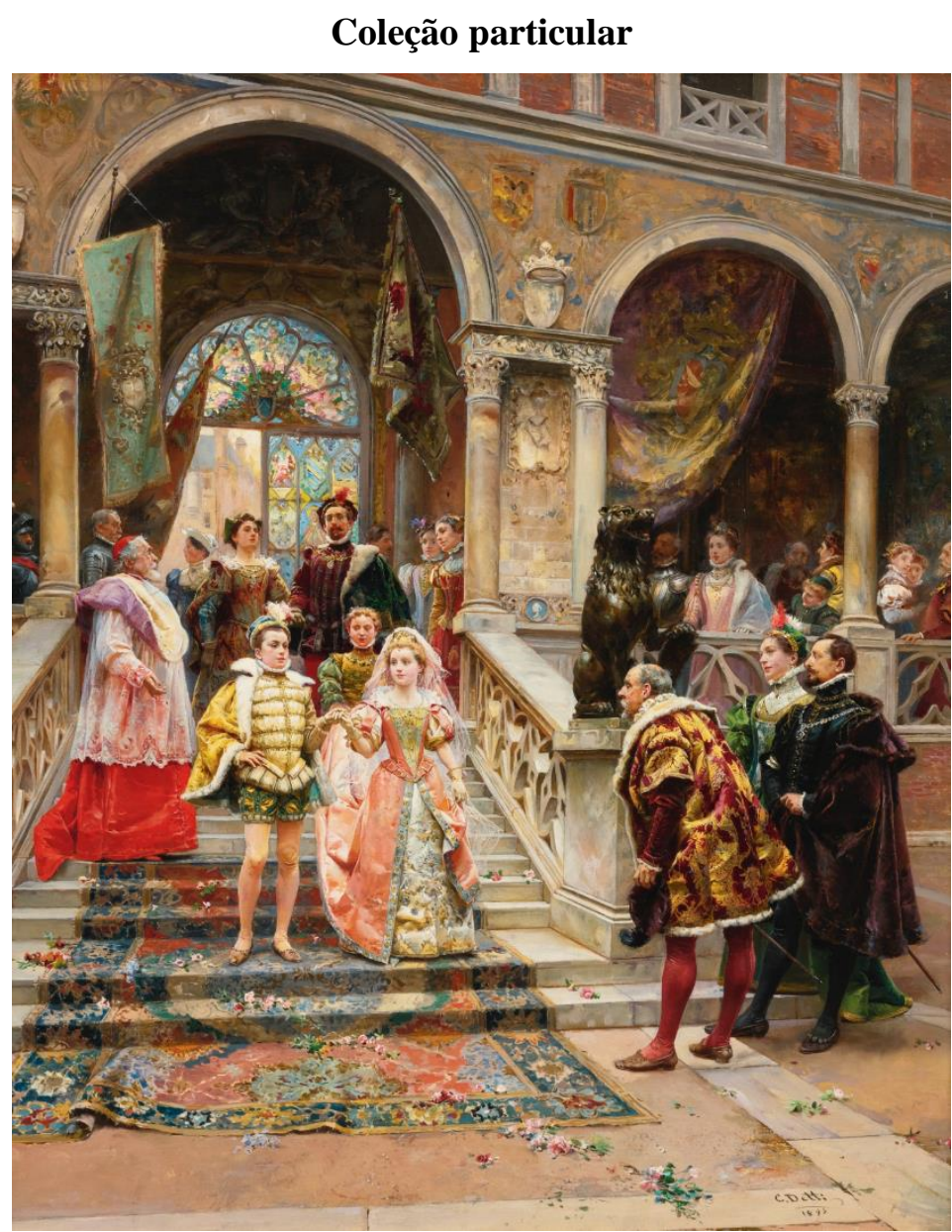

Fonte: artrenewal.org ${ }^{28}$.

Ambientada no final do século XVI, a cena reproduz com precisão os luxuosos figurinos de época de uma corte fictícia. Não se trata de um fato histórico, mas meramente de uma cerimônia principesca indefinida. Que paralelo podemos, então, estabelecer entre esse príncipe, as fantasias dos duques de Guermantes e, também, com o rei, a duquesa e o barão de The Last Banquet? O que estamos tentando entender é se esses príncipes, duquesas, condes ou baronesas devem ser entendidos como representação de estereótipos banais ou de arquétipos ideais? A resposta para essa última pergunta é, provavelmente, "tanto faz". Acreditamos que antes da ascensão da cultura burguesa industrial e da cultura

28 Disponível em: https://www.artrenewal.org/artworks/the-marriage-of-the-prince/cesare-augustedetti/61520. Acesso em: outubro /2020. 
de massa, todo estereótipo era considerado arquetípico ${ }^{29}$, mas, no século XIX, ocorreu uma inversão e todos os arquétipos foram desmascarados e revelam-se como meros clichês. No entanto, essa inversão não é tão simples, pois o príncipe de Detti ainda oscila entre as duas mentalidades. A cena pomposa cria um invólucro ilustre para o príncipe estereotipado, fazendo-o adquirir a arrogância de um arquétipo. Porém, tudo não passa de uma invenção histórica. Significa que a pintura acadêmica converteu-se em uma mercadoria tão esnobe quanto seus espectadores e passou a veicular uma mensagem visual que utiliza os códigos populares da cultura de massa, mas adornada com ornamentos históricos faustosos e ilustres que dissimulam sua banalidade.

Pretendemos, agora, a partir da análise de uma pintura de gênero histórico autorreflexiva, demonstrar como seus ridículos estereótipos esnobes - travestidos de arrogantes arquétipos de nobreza - fundamentam a retórica consumista do século XIX, e de que modo continuam a modelar a comunicação visual contemporânea.

\section{A dimensão crítica da pintura de gênero histórico}

Quando Jacques-Louis David pintou A Coroação de Napoleão (de 1807), subverteu muitos códigos que ele mesmo havia construído ou "reerguido". Esse modelo fundamentava-se em citações eruditas, com intuito de construir uma imagem ética. Desse modo, os temas ambientados no passado clássico transpiravam uma ideologia republicana (NÖEL, 1989, p. 8). Em A Coroação, no entanto, ele construiu um documento contundente que legitimava grande parte da cultura visual esnobe que caracterizaria o século XIX. A partir dessa monumental pintura histórica, David transformou o presente em história (a obra foi concluída em 1807, mas foi encomendada antes da coroação, em 1804). "Temas históricos podiam agora ser encontrados no tempo presente" (NÖEL,

\footnotetext{
${ }^{29}$ De acordo com Peter Burke (2009, p. 31), “ao contrário dos espectadores pós-românticos, que rejeitam o clichê como uma ofensa à espontaneidade, o público do século XVII não tinha, ao que parece nenhuma objeção aos lugares-comuns e às fórmulas". Tudo indica que antes da indústria gráfica e dos jornais populares, os modelos podiam ser ingenuamente considerados ideais singulares e dignos de serem imitados. Burke acrescenta que até o século XVII, ainda existe no Ocidente, uma "mentalidade mística" (p. 139) que permite sacralizar certos modelos, mas na "transição do feudalismo para o capitalismo" (p. 140) essa mentalidade desapareceu. O simbolismo perdeu o poder de magia. Podemos deduzir que isso inviabilizou a construção cultural dos arquétipos, pois foram expostos à sua condição de clichê.
} 
1989, p. 38). David teria dito: "nós não temos mais que procurar na história dos povos antigos temas para exercitar os nossos pincéis" (NÖEL, 1989, p. 38).

Poucos soberanos europeus haviam ousado representar-se em tamanha glória. Porém, essa apoteose de todas as coroações cristãs é uma anticoroação. Não apenas no sentido de que todo o grandioso espetáculo foi armado para tornar evidente e histórica a recusa de Napoleão de ser sagrado (ele teria se autocoroado), mas também porque é uma coroação, diante dos valores feudais, considerada esnobe (sem nobreza). Contudo, paradoxalmente, talvez fosse a maior imagem de uma coroação até então e, além disso, foi exposta no Louvre e apreciada pelas multidões, transformando-se no principal modelo iconográfico de coroação. Carlos X, na restauração do absolutismo, por exemplo, fez-se representar segundo esses mesmos códigos. Outro exemplo interessante é a Coroação de D. Pedro I, pintada por Jean-Baptiste Debret, em 1828. Desse modo, reis e imperadores de tradição feudal se fizeram retratar segundo um modelo esnobe.

A Coroação, de David, desperta uma dimensão crítica sobre a questão aqui levantada, pois mostra que as pinturas de gênero histórico não eram meras cenas esnobes e estereotipadas em contraponto às nobres e arquetípicas ${ }^{30}$ pinturas históricas. Tal como a nobreza europeia havia se aburguesado, a grandiosa pintura histórica também havia se tornado uma mídia esnobe.

É preciso, então, lançar mão de uma última tela que nos ajude a penetrar ainda mais nesta questão. Trata-se de uma obra de Jean-Georges Vibert, pintada por volta de $1900^{31}$, denominada Planejando a Coroação de Napoleão (Figura 6). Podemos caracterizá-la como uma imagem teórica, no sentido utilizado por W. J. T. Mitchell (1995, p. 35-82), na medida em que é uma imagem que reflete sobre sua própria condição e contribui para o aprofundamento da teoria iconológica intermidiática que estamos traçando.

\footnotetext{
${ }^{30}$ Com "nobres e arquetípicas" não queremos dizer que a pintura histórica anterior ao século XIX fosse melhor, apenas não era uma mídia voltada para espectadores esnobes. Eram pinturas feitas para uma cultura erudita extremamente elitista e povoadas por figuras arquetípicas alheias aos estereótipos populares que a cultura de massa iria formular.

${ }^{31}$ Existem outras duas versões da obra, praticamente idênticas a essa, uma com 100 x $141 \mathrm{~cm}$ e outra com $40 \times 56,8 \mathrm{~cm}$
} 
Figura 6 - Planejando a Coroação, de Jean-Georges Vibert (cerca de 1900)

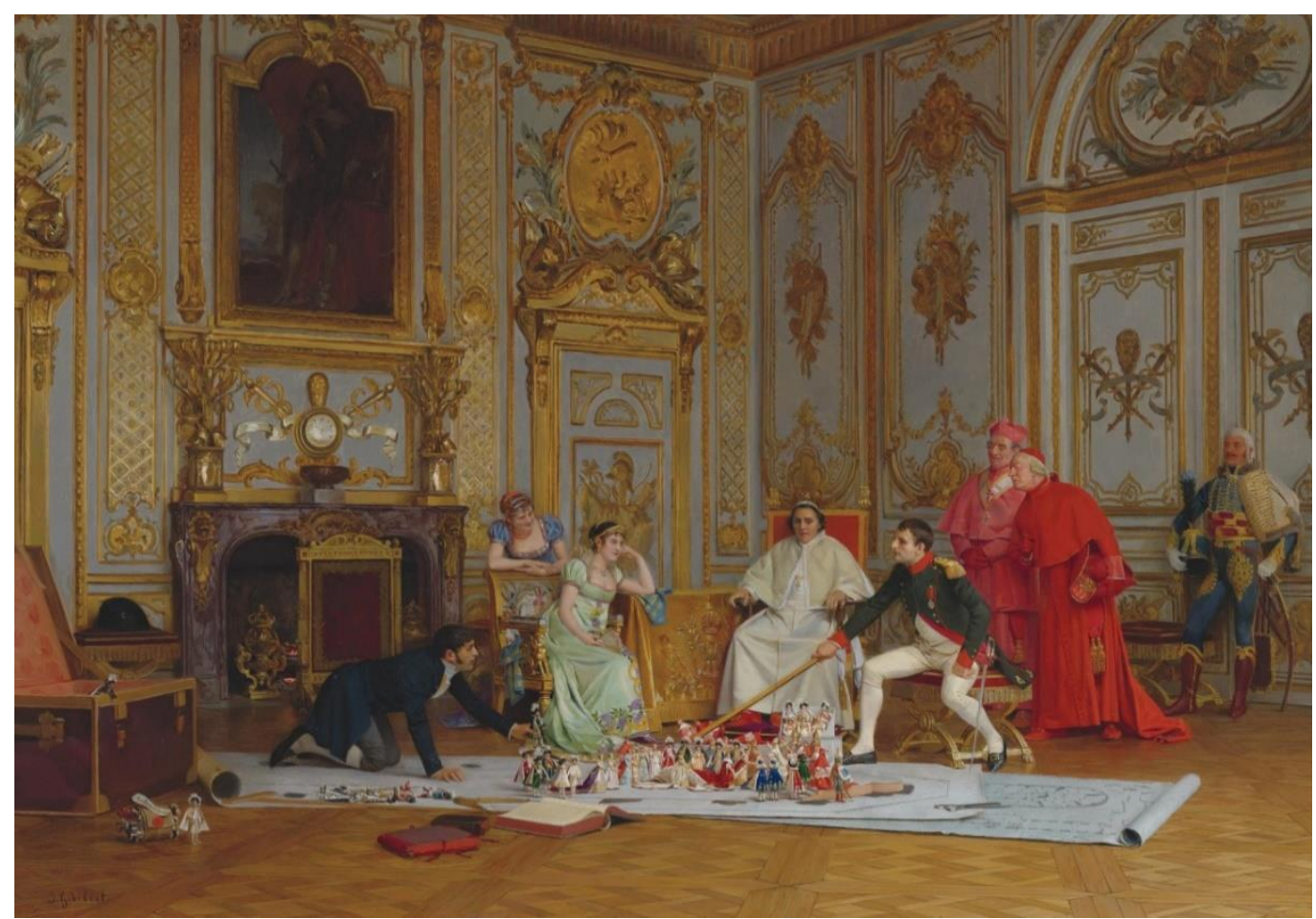

Fonte: Google Imagens ${ }^{32}$.

A tela mostra o mestre de cerimônias do grandioso evento, Jean-Baptiste Isabey (1767-1855), manipulando bonecos, vestidos de acordo com os personagens da Coroação, de Jacques-Louis David, sobre a planta da Catedral de Notre-Dame, em Paris (que lembra o tabuleiro de um jogo). Trata-se de uma cena íntima e jocosa ${ }^{33}$ a respeito de outra cena solene e pública. Contudo, aqui o que mais nos interessa são os bonecos vestidos e perfilados de acordo com a tela de David.

$\mathrm{Na}$ tela de Vibert os protagonistas da Coroação, de David, aparecem representados tanto num momento privado e descontraído (os bastidores da coroação), típico do gênero histórico, quanto como peças que retratam personagens de um momento grandioso, formal, oficial e histórico, típico da pintura histórica, mas transformados em peças num jogo de tabuleiro. A solenidade histórica ganha o aspecto de entretenimento, na medida em que todas as peças foram retiradas de um baú, que se assemelha a uma

\footnotetext{
32 Disponível em: https://bit.ly/3qBRecn. Acesso em: out. 2020.

${ }^{33} \mathrm{Na}$ tela de Vibert, Napoleão, sentado ao lado do Papa Pio VII, afasta com um bastão os bonecos que representam os dois cardeais que estão atrás, olhando assustados.
} 
caixa de brinquedos. Desse modo, as figuras aristocráticas passam a possuir um fundamento arquetípico de outra ordem, ou melhor, de outra escala, equivalente à personagem da Rainha Vermelha, de Lewis $\mathrm{Carrol}^{34}$.

Portanto, a grandiloquência da anti-Coroação esnobe de David, que forjou seu status arquetípico (de modelo exemplar, singular e ilustre), imitado tanto por Carlos X e D. Pedro I, foi triplamente rebaixada pela tela de Vibert. Primeiramente, a tela de Vibert é muito menor. Além disso, os personagens foram retratados com descontração burguesa e, por último, a formalidade elegante das poses históricas converteu-se em miniaturas tão patéticas quanto à Rainha Vermelha, de Lewis Carrol. Porém, essas bonecas, tão menores que os personagens reais que as observam, representam, contraditoriamente, suas identidades históricas privilegiadas, mas reduzidas a peças de jogo de tabuleiro.

$\mathrm{O}$ consumidor burguês que adquirisse a pequena tela de Vibert levaria para o interior de seu lar uma imagem que dialoga com a presença desses personagens na monumental pintura histórica de David, exposta no Louvre. O comprador se identifica com Napoleão aburguesado da tela de Vibert e, por conseguinte, acaba se identificando com o imperador, pintado por David. De modo simplista, pode parecer que esses arquétipos públicos preenchem o estereótipo doméstico. Entretanto, a tela de Vibert mostra que esse preenchimento é um artifício tão frágil como assumir a personalidade de uma peça durante uma partida de um jogo de tabuleiro. A mensagem que uma pintura de gênero histórico comunica é uma promessa esnobe que só pode se realizar plenamente dentro dos limites lúdicos de uma brincadeira. O que este artigo questiona, então, é se esse seria um dos fundamentos da comunicação visual no século XIX?

O que podemos dizer, no momento, é que a comunicação visual, naquela época - em mídias como cartazes ou pinturas de gênero histórico - visava despertar o desejo de consumo por meio de uma mentalidade parvenu $^{35}$. Comunicava aquilo que faltava. E o que mais fazia falta a essa sociedade esnobe era a nobreza, que não estava disponível justamente porque era uma sociedade burguesa sine nobilitate. A tela de Vibert, no entanto, não parece ser uma obra passiva diante desse paradoxo, pois expõe essa crise da

\footnotetext{
${ }^{34}$ Isso ocorre quando, no final de Alice através do espelho, a Rainha Vermelha "reduzira-se subitamente ao tamanho de uma bonequinha" (CARROL, 2002, p. 257, 259), afinal era uma mera peça de xadrez.

35 Termo pejorativo utilizado para caracterizar burgueses novos ricos no século XIX.
} 


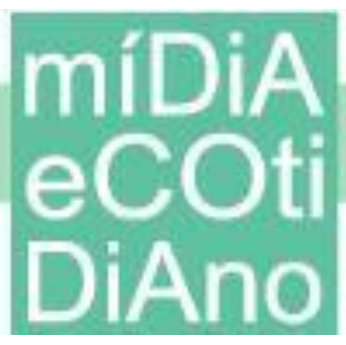

ausência e consegue mostrar de modo irônico que em vez de comprar uma pintura de gênero histórico com a finalidade de consumir figuras comuns, emulando personagens ilustres, basta comprar uma caixa com brinquedos estereotipados que remetam aos grandes arquétipos da tradição histórica. Significa que comprar um jogo para poder assumir a personalidade de um rei ou de um barão, durante uma partida, transformará o consumidor em um nobre, tanto quanto adquirir ou portar um título de nobreza em uma sociedade esnobe.

\section{Considerações finais}

Antes de finalizar, é preciso refletir sobre em que medida o esnobismo do século XIX sobrevive no consumidor do século XXI.

Vimos que a pintura de Vibert - na virada do século XIX para o XX - mostra a pulsação entre o arquétipo e o clichê que pontuou o surgimento da pintura de gênero histórico e a estética da invenção da história. O quadro mostra que dentro daquela cultura burguesa, o príncipe de Detti (Figura 5) era, contraditoriamente, ao mesmo tempo, um modelo ideal, assim como um simulacro.

Em The Last Banquet, por sua vez, essa pulsação talvez não seja mais uma questão. Vivemos em uma cultura pós-Kafka, em que adquirimos a consciência de que o conde, senhor d'O Castelo, é o outro ou o poder opressor da nobreza de um tempo que já passou. Desse modo, encaramos The Last Banquet como um jogo banal, cujos participantes assumirão as alteridades momentâneas e esdrúxulas de reis, duquesas ou barões de coisa alguma, sem nenhuma preocupação esnobe. Isso ocorre não porque o consumidor contemporâneo conseguiu resolver esse vazio, mas simplesmente porque os estereótipos se afastaram dos pomposos arquétipos e ganharam outras configurações menos arrogantes. É difícil pensar em pessoas, além de crianças de sete anos de idade, construindo suas identidades de vorazes consumidoras mirins através do arquétipo-clichê das princesas da Disney. Desse modo, jogar The Last Banquet é um passatempo 
historicista que só consegue afetar a identidade adulta de imaginativos $n e r d s^{36}$, pois, para a maioria dos jogadores, provavelmente, funcionará como mero entretenimento sem maior importância.

Por outro lado, o potencial metalinguístico da pintura de Vibert consegue, também, estabelecer um diálogo entre a gigantesca pintura de David e o pequeno jogo de cartas do último banquete, pois as miniaturas sobre a planta da Catedral de Notre-Dame remetem tanto a uma pintura histórica esnobe, quanto a um brinquedo. Coloca-nos diante da analogia entre o burguês, do século XIX, que adquiria um título de nobreza e o jogador contemporâneo, que assume a personalidade de um duque, em The Last Banquet, e nos faz pensar se aquela comunicação visual (composta por estereótipos travestidos de arquétipos), motivada por uma ideologia obsessivamente esnobe ainda sobrevive.

Portanto, jogar The Last Banquet pode também servir como uma atitude reflexiva complementar à tela de Vibert, pois nos coloca em um papel evidentemente bufo (uma das opções é o papel de bobo da corte), de ter comprado um jogo que nos autoriza ser, por algumas horas, um ilustre arquétipo contundentemente estereotipado. Não se trata mais de uma atitude claramente esnobe, na mediada em que não desejamos realmente assumir aquelas identidades burlescas além dos limites lúdicos do jogo. No entanto, as ilustrações das cartas comicamente pedantes da duquesa-megera ou do maquiavélico barão (Figura 7) não são somente uma iconografia caricata do desejo de consumo fundamentalmente excludente do século XIX, que vimos na pintura de gênero histórico. São também, caricaturas risíveis dos modelos veiculados pela publicidade moderna ${ }^{37}$.

\footnotetext{
${ }^{36}$ São um tipo de consumidor diferenciado que possui uma imaginação fértil, capaz de produzir uma fantasmagoria tão densa que supera efetivamente a sensação de ausência, despertada pelo desejo de consumo, na medida em que conseguem vivenciar plenamente a história inventada por $O$ Senhor dos Anéis, Game of Thrones, Guerra nas Estrelas, entre outras.

${ }^{37}$ Umberto Eco (1976) identifica na publicidade do século XX o uso de estereótipos ilustres que funcionam de modo semelhante ao modelo aristocrático do século XIX. Ao analisar um anúncio de sabonete, afirma que os personagens remetem às elites europeias e que passam a seguinte mensagem para a classe média: "pessoas de classe devem ser imitadas - se os que pertencem à alta sociedade agem assim, porque não devem vocês fazer o mesmo?" (p. 167-168).
} 


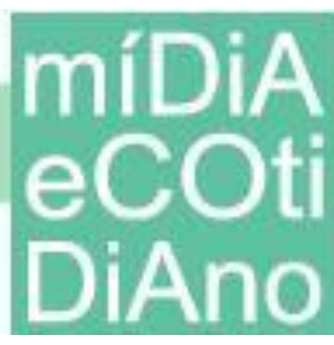

\section{PPGMC}

Figura 7 - Barão e Duquesa (cartas do jogo The Last Banquet)
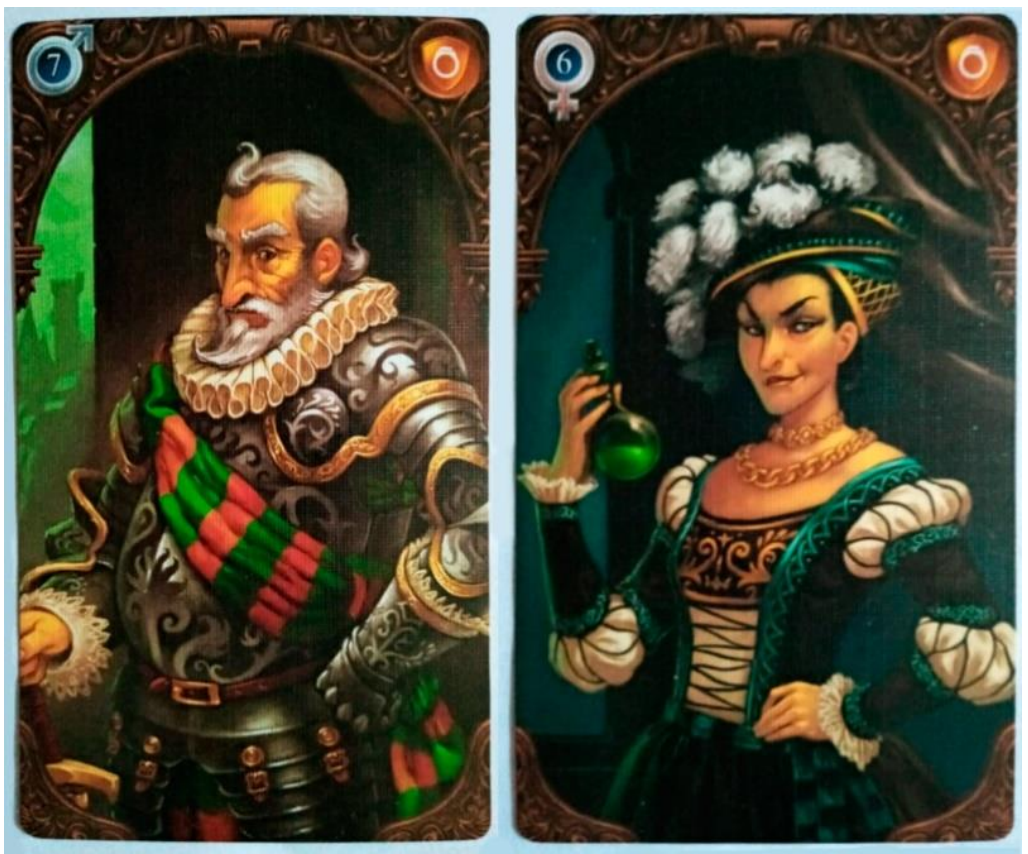

Fonte: Fotografia dos autores.

Jogar The Last Banquet é, de maneira crítica mais óbvia, assumir momentaneamente a identidade de um cortesão patético e reconhecer como eram kitsch e tolos os indivíduos parvenus do século XIX, perseguindo uma autoimagem tão fantasiosa e irreal que, para nós, é como um conto de fadas. O fetiche historicista, irresistível no século XIX, adquiriu uma aparência de sedução infantil. Porém, jogar The Last Banquet é também, olhar-se no espelho (as cartas) e ver que nós, consumidores modernos, persistimos em perseguir uma ausência. Continuamos a ser almas ocas e sedentas, tal como Drácula. Desejamos, ardentemente, embriagar-nos do sangue dos bens de consumo banais e desnecessários com a finalidade de legitimar identidades igualmente excludentes $^{38}$ (dos que possuem mais do que precisam), que continuam a ser forjadas por meio de histórias inventadas por narrativas veiculas pelas novas mídias de comunicação de massa.

\footnotetext{
${ }^{38}$ Jean Baudrillard (2004, p. 191-193) explica que a ideologia do consumo se baseia no sonho de adquirir "objetos que distinguirão você dos outros" e que "queremos ainda o que os outros não têm", mas contraditoriamente esse objeto é um modelo padronizado (estereotipado) oferecido a todos que puderem comprar.
} 


\section{Referências}

ALVIM, Pedro de Andrade. O arquivo e a busca de visibilidade - pinturas de "gênero histórico" nos álbuns fotográficos dos Salões de Paris. Revista Arte \& Ensaios, n 20, ano XVII, p. 8693, jul. 2010.

BALZAC, Honoré. Ilusões perdidas. São Paulo: Cia. das Letras, 2016.

BANN, Stephen. As invenções da história: ensaios sobre a representação do passado. São Paulo: UNESP Editora, 1994.

Paul Delaroche: history painted. London: Reaktion Books Ltda, 1997.

. The Clothing of Clio: a study of the representation of history in nineteenth-century

Britain and France. Cambridge: Cambridge University Press, 2010.

BAUDRILLARD, Jean. O sistema dos objetos. São Paulo: Perspectiva, 2004.

BELOZERSKAYA, Marina. Rethinking the Reaissance: burgundian arts across Europe. Cambridge: Cambridge University Press, 2012.

BURKE, Peter. A fabricação do rei, a construção da imagem pública de Luís XIV. Rio de Janeiro: Zahar, 2009.

CARROL, Lewis. Alice. Edição comentada. Rio de Janeiro: Jorge Zahar Editor, 2002.

CERQUEIRA LEITE, Beatriz Westin de. A Arte como Expressão da Glória: Napoleao Bonaparte. São Paulo: Editorial Altamira, 2011.

DENIS, Rafael Cardoso. Uma introdução à história do design. São Paulo: Ed. Edgard Blücher, 2000.

DUBY, Gerorges. As Três Ordens ou o imaginário do feudalismo. Lisboa: Editorial estampa, 1982.

DUMAS PAI, Alexandre. O Conde de Monte Cristo. São Paulo: Martin Claret, 2008. v. 1.

ECO, Umberto. A estrutura ausente. São Paulo: Perspectiva, 1976.

ELIAS, Norbert. A sociedade de corte. Rio de Janeiro: Zahar, 2001.

GOTLIEB, Marc. The plight of emulation: Ernest Meissonier and french salon painting. New Jersey: Princeton University Press, 1996.

HIBBERT, Christopher. Ascensão e queda da casa dos Medici. São Paulo: Cia. das Letras, 1993.

LICHTENSTEIN, Jacqueline (org.). A pintura: os gêneros pictóricos. São Paulo: Editora 34, 2006. v. 10. 
LE GOFF, Jacques. A civilização do ocidente medieval. Bauru: Editora EDUSC, 2005.

MARKOV, Walter. Grand Empire: virtue anda vice in the napoleonic era. Leipzig: Edition Leipzig, 1990.

MITCHELL, W. J. T. Metapictures. In: MITCHELL, W. J. T. Picture theory. Chicago: The University of Chicago Press, 1995.

NÖEL, Bernard. David. New York: Crown Publishers, 1989.

PROUST, Marcel. O caminho de Guermantes. Rio de Janeiro: Ediouro, 2002.

WHITMORE, Janet. Cesare Auguste Detti, The Marriage of the Prince. Disponível em: http://www.tuttartpitturasculturapoesiamusica.com/2014/08/Cesare-Augusto Detti.html. Acesso em: 12 dez. 2016.

WILSON, Derek. Rothschild: a story of wealth and power. London: WSOY, 1994.

WOLF, Norbert. The art of the salon: the triumph of 19th century painting. London: Prestel Verlag, 2012. 